\title{
ORBITAL COLOUR DOPPLER IMAGING
}

\author{
NEIL S. ABURN and ROBERT C. SERGOTT \\ Philadelphia, USA
}

\begin{abstract}
SUMMARY
Colour Doppler imaging (CDI) is an ultrasonic method for qualitatively and quantitatively assessing blood flow. Recently this technique has been adapted for investigation of the orbital, optic nerve and ocular vasculature. We discuss the history, principles and methodology of this examination technique for ophthalmology. Also described are normal haemodynamic characteristics as well as the findings in common pathological states involving derangements of orbital blood flow. Although CDI is relatively new to ophthalmology it has already proved to be of benefit in conditions with altered orbital, ocular and optic nerve blood flow. In the future it is expected that the indications for and applications of CDI will become more clearly defined and that orbital CDI will be more widely available and utilised, especially in the investigation of vascular diseases of the orbit, optic nerve and retina.
\end{abstract}

Colour Doppler imaging (CDI) is an ultrasonic imaging modality which allows the display of blood flow characteristics on a real-time grey-scale B-mode background. This technique was initially described in $1979^{1}$ and originally became widely used in cardiological investigations and more recently in investigation of the peripheral vascular system as well as other organ systems. ${ }^{1-5}$

Investigation of disorders of the orbit with CDI was first reported in $1989 .{ }^{5}$ Since then CDI has proved to be a valuable technique for investigation of numerous orbital and ocular conditions. The most important group of these disorders for which CDI has proved useful are those involving alterations in haemodynamics and perfusion of the eye. In the future, this technique may enhance our concepts of the pathophysiology of ischaemic disorders of the eye and optic nerve and also the effect of various treatment modalities on these underlying abnormalities.

\section{PRINCIPLES}

Conventional B-mode (brightness modulated) ultrasound imaging requires the use of a transducer to provide information about an acoustical cross-section of tissue which is eventually displayed in a two-dimensional grey-scale

Correspondence to: Robert C. Sergott, MD, Neuro-Ophthalmology Service, Wills Eye Hospital, Ninth and Walnut Streets, Philadelphia, PA 19107, USA. image. ${ }^{6}$ The brightness of each dot in the displayed image is proportional to the amplitude of the echo received from that point in the target tissue. Real-time B-scan imaging is obtained by a high frequency of sampling and display (usually between 10 and 60 times per second). The best images are obtained from structures oriented perpendicularly to the ultrasound beam. ${ }^{6}$ This form of imaging does not record information from small, i.e. low-amplitude targets that are moving rapidly - most importantly, erythrocytes flowing at normal velocities in blood vessels. ${ }^{3}$

Doppler imaging is based on the Doppler principle that sound waves emanating from a source will vary in frequency depending on the relative movement between the source and the receiver. ${ }^{7}$ This effect was first described at a meeting in Prague in 1842 by Johann Christian Doppler, a Salzburg-born physicist (Fig. 1). His theories were published in 1843 under the title "Ueber das farbige Licht der Doppelsterne und einiger anderer Gestirne des Himmels' ('On the Coloured Light of Double Stars and some Other Heavenly Bodies' (Fig. 2). ${ }^{8,9}$ The Doppler effect is defined by the formula:

$$
D f=2 F V \cos \theta / c
$$

where $D f$ is the measured frequency shift, $F$ is the frequency of the sound when the source is at rest, $V$ is the velocity of the source, $\theta$ is the angle between the line of motion and the line of measurement and $c$ is the velocity of propagation of the sound in the medium under consideration. In ultrasonic imaging Doppler information is derived from frequency shifts between emitted and recorded sound waves at the transducer; thus, as the frequency shift can be measured and the other factors in the equation are known, the velocity of the reflecting source can be calculated.

In contrast to B-scan information, Doppler imaging is ideally performed parallel to the direction of movement, i.e. at an angle of $0^{\circ}$. In the orbit, Doppler information (i.e. frequency shifts) is recorded only from blood flow, in the absence of movement artefacts.

Duplex scanning is a technology combining B-scan with Doppler analysis that enables the gathering of Doppler information from known locations as represented in the B-scan image. ${ }^{6}$ This technique is appropriately used in 


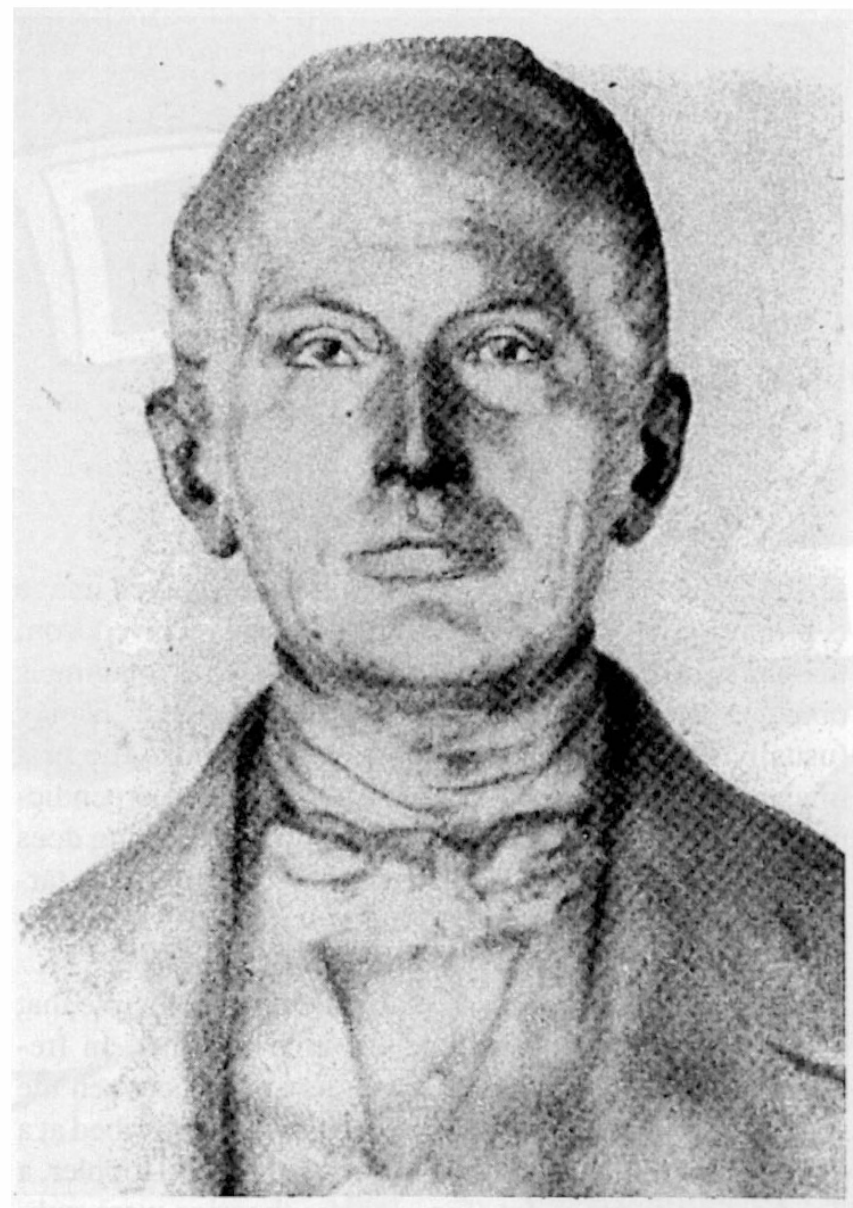

Fig. 1. Bust of Joham Christian Doppler. (B) courtesy of Pergamon Press.)

situations where the B-scan image provides sufficient resolution for the Doppler sampling to be performed at a known location, that is, in a readily identifiable segment of a readily identifiable vessel such as in duplex scanning of the carotid arterial system in the neck. However, the orbital blood vessels are small and accurate placement of the Doppler sample volume on the information carried in a B-scan grey-scale image is difficult. Another limitation is that the Doppler angle is unknown, which further reduces the validity of results obtained." 12

Transcranial Doppler is an ultrasonic technique by means of which the basal intracranial arteries can be insonated through 'windows' in the skull." This method of vascular assessment was first described in 1982 $2^{14}$ and more recently investigation of blood flow in the ophthalmic artery has been estimated using the same technology. ${ }^{15-17}$ Unfortunately, this method has a number of drawbacks in the assessment of orbital blood flow. The probe frequency is necessarily low to be able to insonate through bone. ${ }^{13}$ thus reducing the potential resolution of these systems; this is obviously of significance when dealing with the small orbital blood vessels. Also there is no direct visualisation of the vessel being insonated. which is a potential source of error as the angle of insonation is never certain ${ }^{17}$ and it is likely that errors of vessel identification or blood flow direction might easily be made. especially in cases with tortuous vessels or greatly deranged blood flow parameters.

Current CDI technology enables Doppler information to be gathered from a cross-section of tissue simultaneously with the B-scan information: thus, the colour blood flow image from the entire field can be accurately superimposed on the grey-scale real-time image. The transducer emits pulses of ultrasound with set parameters and the reflected ultrasound beam is analysed for amplitude, phase and frequency. ${ }^{+}$The recorded amplitude provides the raw data for production of the grey-scale image. The phase information indicates the presence and direction of motion while the frequency and therefore frequency shift indicates the velocity by Doppler calculations. Each small area of target tissue is represented in the memory of the scanning device at a particular address. A value is assigned to each address depending on the recorded direction of flow and the averaged flow velocity. This assigned flow velocity is an average because even in a small sample area a range of trequency shifts will be recorded. ${ }^{2+4}$ This value is represented in the image as a small block of colour (pixel) at a particular position on the displayed image. In orbital CDI blood flow towards the transducer (usually arterial) is encoded as red and flow awaly from the transducer (usually venous) is encoded as

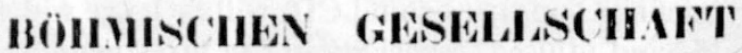

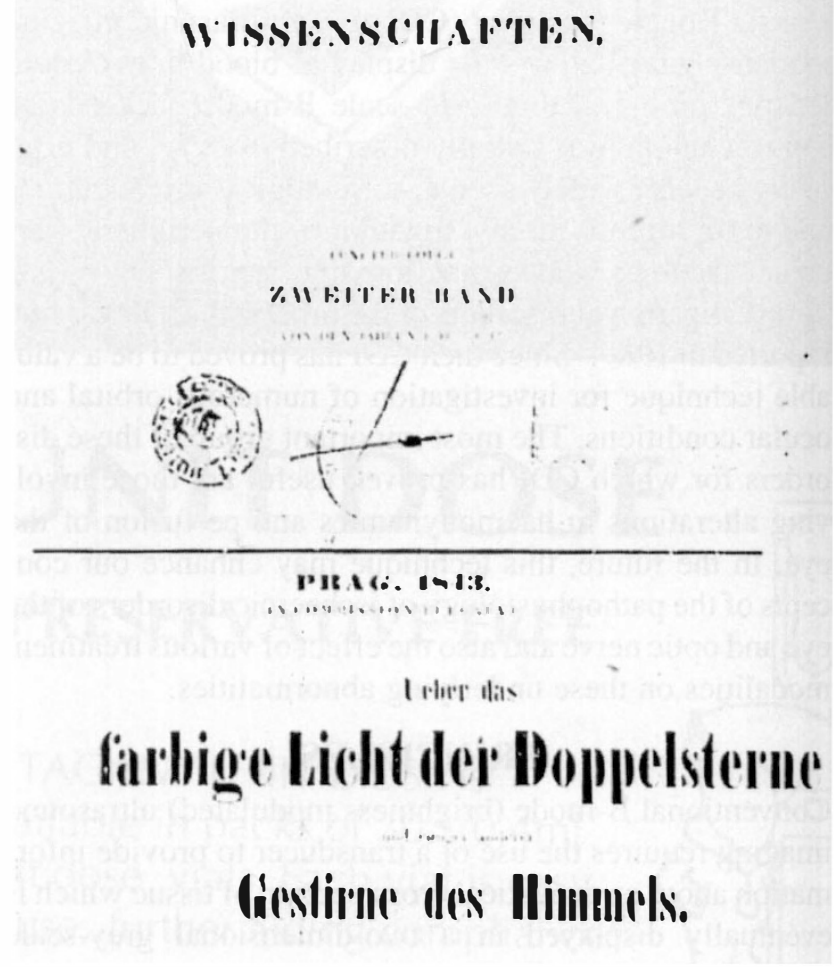

Fig. 2. Frontispice of Doppler's original publication. (By conteriy of Pergamon Press.) 
blue. The colour saturation indicates the velocity - higher saturation occurring at lower blood flow velocities. The colour Doppler image therefore provides a good semiquantitative indication of blood flow parameters, but currently it is less than ideal for accurate quantitative assessment.

Pulsed Doppler with spectral analysis is used in conjunction with the colour Doppler image for accurate quantification of the flow characteristics of vessels. Using this technique ultrasound is used in short pulses to sample a small part of the field. This provides graphic, and auditory, representation of blood flow with frequency shifts (represented as velocity) plotted against time, i.e. it provides temporal representation of flow characteristics as compared with the spatial representation of the colour Doppler image. Flow towards the probe is represented above the $x$-axis and flow away from the probe below the $x$-axis. Spectral analysis can be performed on this information and flow characteristics can be calculated with accuracy if the angle of sampling with regard to the vessel being sampled is known. With the use of CDI the placement and correct orientation of the pulsed Doppler sample volume is simplified. In addition to diastolic, systolic and mean flow velocities, the mean pulsatility of flow can also be calculated. The pulsatility (also referred to as Gosling's pulsatility index) provides an assessment of vascular resistance and is calculated using the formula: ${ }^{10,18}$ $\begin{gathered}\text { Pulsatility } \\ \text { index }\end{gathered}=\frac{\text { Peak systolic velocity }- \text { end-diastolic velocity }}{\text { Average velocity }}$

Another less frequently used ratio is the resistivity index (also known as Pourcellot's ratio), which is calculated as follows: ${ }^{10}$

$\begin{gathered}\text { Resistivity } \\ \text { index }\end{gathered}=\frac{\text { Peak systolic velocity }- \text { end-diastolic velocity }}{\text { Peak systolic velocity }}$

With the aid of CDI pulsed Doppler spectral analysis can be performed in multiple sites on one or more blood vessels enabling calculation of flow rates in different sections of vessels and in separate vessels.

\section{TECHNIQUE}

There are a number of units suitable for orbital CDI. Our patients described in this paper were all examined with the same unit (QAD 1, Siemens-Quantum Medical Systems, Issaquah, Washington) using a 5.0 or $7.5 \mathrm{MHz}$ transducer. The examination technique (Fig. 3) has been described in detail previously. ${ }^{19}$ In brief, the transducer is applied to the closed lids using an ultrasonic contact gel (sterile methylcellulose) with the patient in a supine position. Scans can be performed in vertical and horizontal planes. To minimise artefacts there should be an absence of patient movement and lack of downward pressure with the transducer.

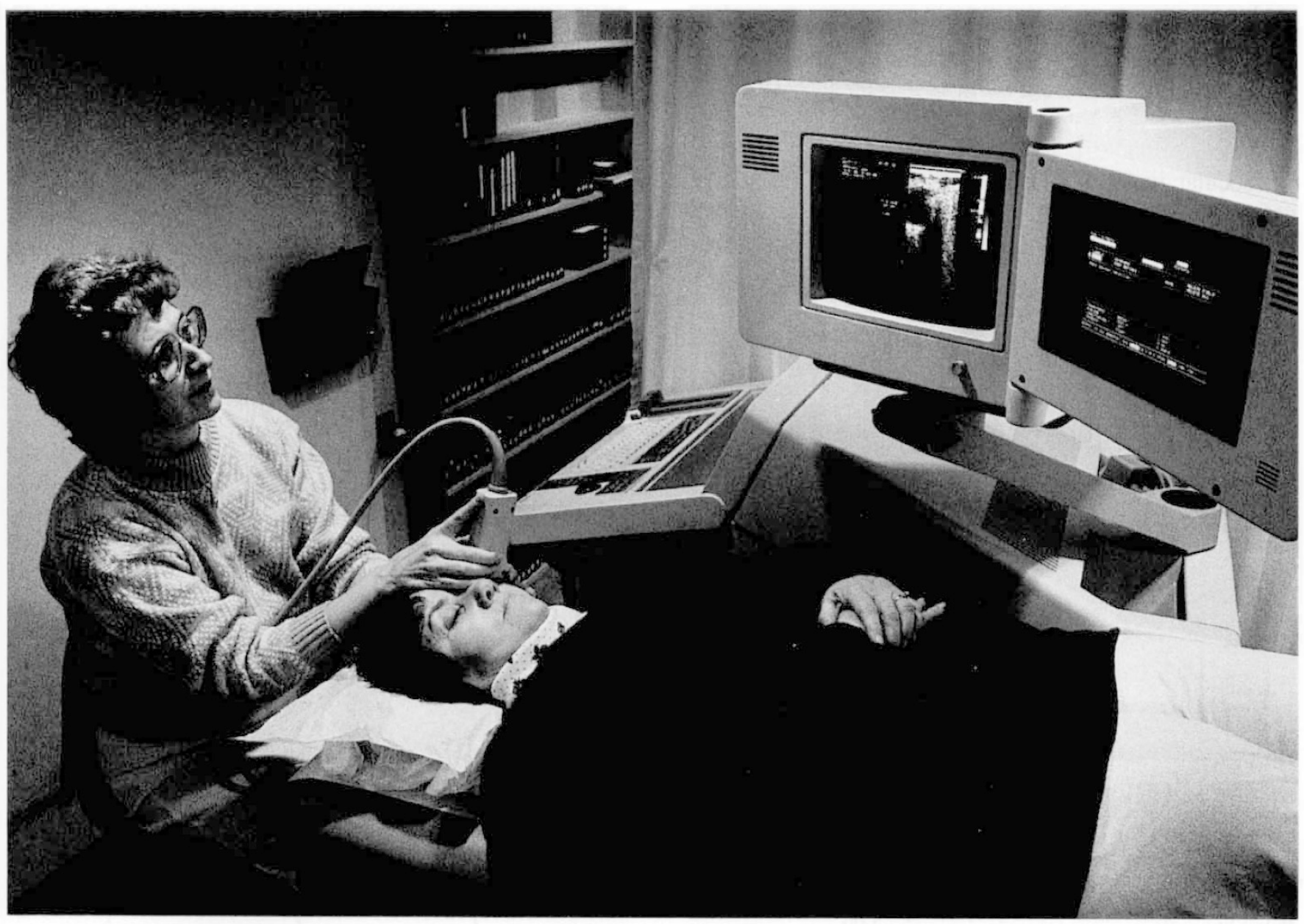

Fig. 3. The positioning of patient, examiner and probe during colour Doppler imaging (CDI). 
In the CDI mode the estimated in situ peak temporal average (SPTA) intensity is $2-3 \mathrm{~mW} / \mathrm{cm}^{2}$. The SPTA intensity is significantly higher in the pulsed Doppler spectral analysis mode at approximately $71 \mathrm{~mW} / \mathrm{cm}^{2}$. This exceeds the current United States Food and Drug Administration (FDA) guidelines of $17 \mathrm{~mW} / \mathrm{cm}^{2}$ but is lower than the upper limit suggested by the American Institute for Ultrasound in Medicine. It is also lower than the FDA recommended maximum for transcranial Doppler using the orbit as a window, which is $96 \mathrm{~mW} / \mathrm{cm}^{2}$. Also, this higher energy level is used only for a brief part of each orbital CDI examination. A major reason for this brief exposure time is that the information contained in the colour Doppler image enables accurate placement of the spectral analysis sample volume. The scanning rate of this equipment is 23 times per second with our most commonly used parameters. The pixel area is $0.62 \mathrm{~mm}^{2}$ and the sample area for pulsed Doppler spectral analysis is $0.2 \mathrm{~mm} \times 0.2 \mathrm{~mm}$.

Informed consent is obtained from all our patients before they are examined using this technique. The only complication experienced by our patients has been mild irritation from the methylcellulose gel.

\section{NORMAL FINDINGS}

As previously described the image obtained with orbital CDI consists of a real-time B-scan image with superimposed blood flow information. This enables CDI to display normal and abnormal structures as well as the extrinsic and intrinsic blood flow associated with these structures.

Normal orbital structures including the eye, optic nerve, extraocular muscles and lacrimal gland are well delineated on CDI. Also visible are intraocular features including the ciliary body, lens, anterior chamber and vitreous cavity (Fig. 4).

\section{Orbital Vasculature}

The ophthalmic artery (OA) is the first branch of the internal carotid artery. It enters the orbit through the optic canal in the company of the optic nerve. Its orbital course can be

Table I. Normal blood flow velocities $(\mathrm{cm} / \mathrm{s})$ and pulsatilities with colour Doppler imaging

\begin{tabular}{lcc}
\hline & Mean & SD \\
\hline Ophthalmic artery & & \\
Systolic & 31.3 & 4.2 \\
Diastolic & 8.3 & 3.9 \\
Average & 15.2 & 4.1 \\
Pulsatility & 1.55 & \\
Central retinal artery & & \\
Systolic & 10.1 & 1.9 \\
Diastolic & 2.6 & 1.2 \\
Average & 4.9 & \\
Pulsatility & 1.52 & \\
Short posterior ciliary artery & & 4.2 \\
Systolic & 12.4 & 2.2 \\
Diastolic & 4.3 & 2.6 \\
Average & 7.6 & \\
Pulsatility & 1.09 & \\
\hline
\end{tabular}

divided into three parts. In the first part it runs anteriorly in the orbit infero-laterally to the optic nerve and then curves before crossing the optic nerve nasally in mid-orbit (the second part). In about $85 \%$ of cases the artery crosses superiorly to the optic nerve; in the remainder of instances it crosses inferiorly. ${ }^{20,21}$ Nasal to the optic nerve (the third part) the vessel divides into its terminal branches. With $\mathrm{CDI}$ the $\mathrm{OA}$ is detected deep in the orbit and under normal conditions it will be imaged in red indicating flow towards the transducer. Temporal spectral analysis of the waveform of the OA gives a pattern with a steep systolic peak and a low diastolic flow velocity (Fig. 5). ${ }^{19}$ Average measured blood flow velocities in the OA (as well as central artery and short posterior ciliary arteries) are shown in Table I. These figures are in close agreement with those obtained by others. ${ }^{12,22}$

The central retinal artery (CRA) leaves the second part of the OA and enters the inferior surface of the optic nerve about $12 \mathrm{~mm}$ behind the globe. ${ }^{23}$ It then runs forward in the substance of the optic nerve until the eye is reached. Within the optic nerve the CRA runs in close proximity to the central retinal vein $(\mathrm{CRV}) .{ }^{23}$ With orbital CDI the CRA and CRV are easily identified within the optic nerve and their colour images are immediately adjacent to each other (Fig. 6). On temporal spectral analysis the two waveforms are, usually, therefore recorded together, the CRA waveform being represented above the $x$-axis and that of the CRV below the $x$-axis (Fig. 6). Note that the CRA waveform shows pulsatile arterial flow with a steep systolic peak suggesting a high-resistance distal vascular bed. The CRV shows a much more continuous waveform but with a small degree of pulsatility. As the two waveforms are generally recorded simultaneously exact quantification of the CRA velocities is more difficult than in other vessels; therefore the mode rather than mean velocities are recorded. In the small percentage of cases where the two vessels can be separately imaged we continue to measure the mode values for CRA flow. When the CRA and CRV are imaged separately CRV parameters can also be recorded.

The long and short posterior ciliary arteries (PCAs) include about six to eight short and two long PCAs which all enter the eye posteriorly near the optic nerve to supply the choroid (short PCAs) and iris and ciliary body (long PCAs). The long and short PCAs are the terminal branches of two or three trunk PCAs which arise at varying sites from the second part of the ophthalmic artery. ${ }^{20,24}$ Usually at least one nasal and one temporal short PCA can be imaged using the CDI system adjacent to the optic nerve just posterior to the globe (Fig. 7). The waveform of these arteries shows less pulsatility than the CRA, consistent with the lower resistance of the uveal (mainly choroidal) vascular bed as compared with the retina. The long PCAs can be identified slightly further from the optic nerve and the trunk PCAs can also frequently be imaged, albeit more posteriorly coursing adjacent to the optic nerve.

Also the supraorbital and supratrochlear arteries are frequently identified in the anterior orbit or periorbitally. 


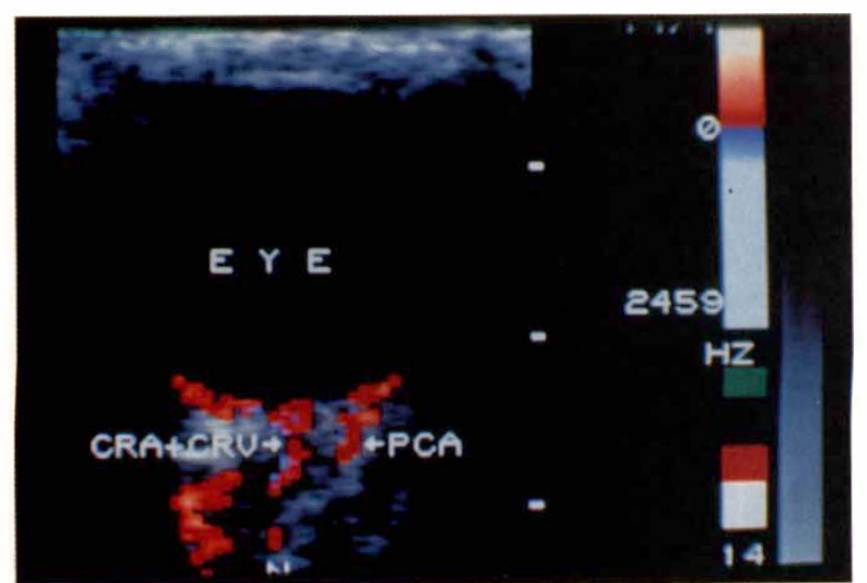

Fig. 4. Colour Doppler image of normal eye showing central retinal artery $(C R A)$, central retinal vein $(C R V)$ and a short posterior ciliary artery $(P C A)$.

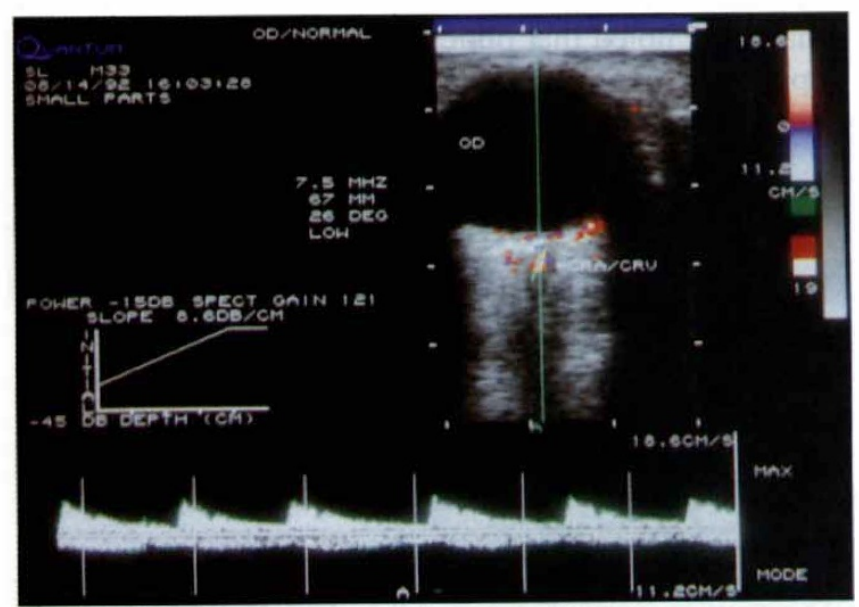

Fig. 6. Colour Doppler image of normal central retinal artery $(C R A)$ and central retinal vein $(C R V)$ with simultaneous spectral analysis of both vessels (pulsatile waveform of CRA is above the axis and continuous waveform of CRV is below the axis).

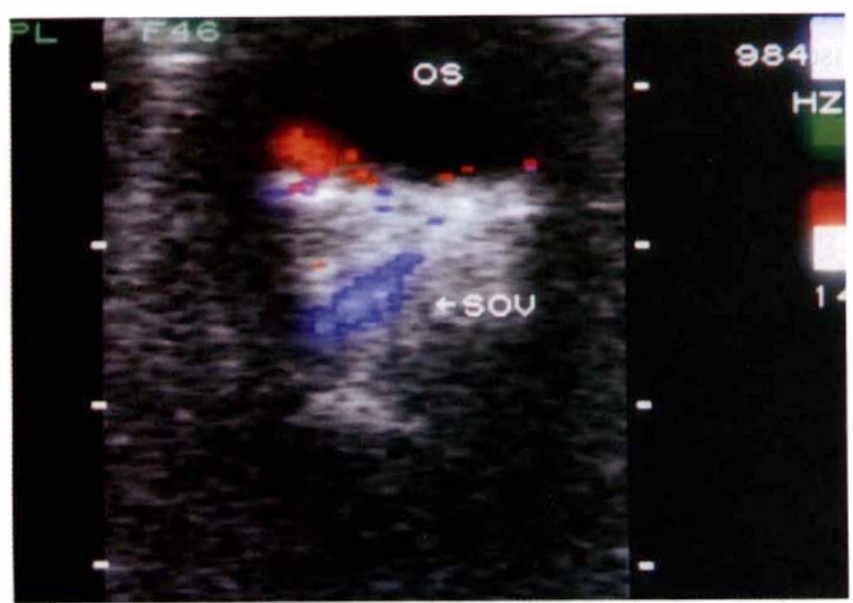

Fig. 8. Magnified colour Doppler image of normal superior ophthalmic vein (SOV).

The superior ophthalmic vein (SOV) courses from the anterosuperiomedial orbit to enter the cavernous sinus via the superior orbital fissure. It can be identified in approxi-

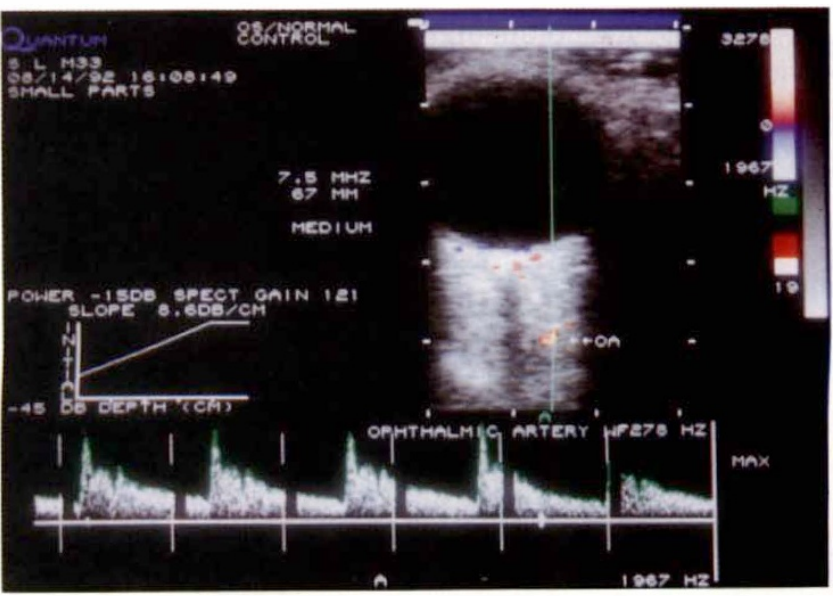

Fig. 5. Normal ophthalmic artery $(O A)$. Note the steep systolic peak of the waveform with spectral analysis.

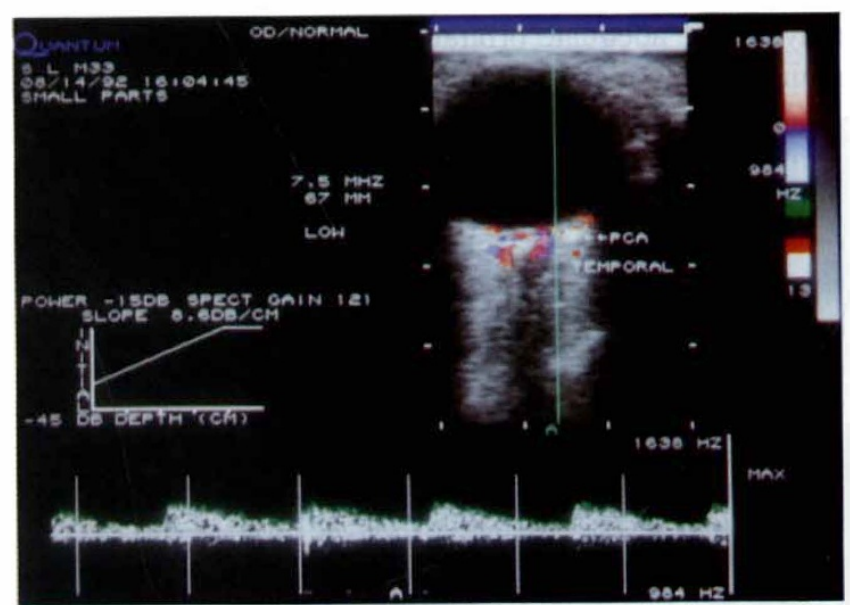

Fig. 7. Colour Doppler image of normal temporal short posterior ciliary artery $(P C A)$.

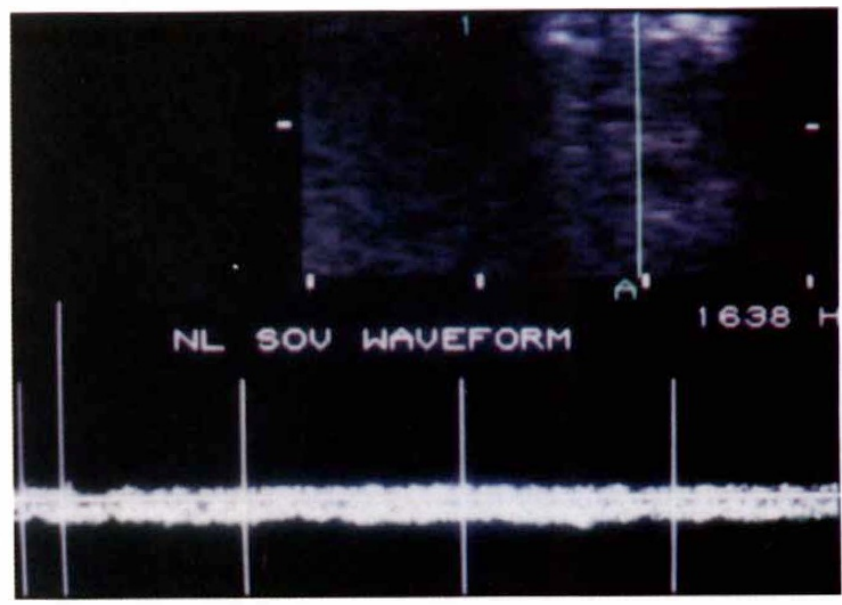

Fig. 9. Normal superior ophthalmic vein (SOV) waveform. Note the lack of pulsatility.

mately $90 \%$ of normal orbits. ${ }^{5.25}$ The colour flow signal is, under normal circumstances, blue indicating flow away from the transducer (Fig. 8). The Valsalva manoeuvre 
may increase the colour signal in some cases or reverse it in others. On temporal spectral analysis the SOV is shown to have a low flow continuous waveform (Fig. 9).

Other veins demonstrable on orbital CDI include the inferior ophthalmic vein, the vortex veins and some periorbital veins.

\section{PATHOLOGICAL CONDITIONS}

\section{Carotid Disease}

Significantly reduced carotid blood flow secondary to vaso-occlusive disease will necessarily result in reduced anterograde ophthalmic artery flow. ${ }^{26}$ If this reduction in flow is severe, reversal of flow in the ophthalmic artery may result ${ }^{27}$ - the ophthalmic artery in these circumstances functioning as an external-internal carotid shunt. There is controversy as to the significance of the contribution of reversed ophthalmic artery blood flow to cerebral perfusion ${ }^{15,28}$ but, in any case, such reversal of flow may enable adequate orbital and ocular blood flow to be maintained in many (but not all) cases.

Orbital CDI studies may show reduced flow velocities in the OA or reversal of flow - indicated by blue encoding of OA blood flow on the colour image and negative blood flow measurements with temporal spectral analysis (Fig. 10). With or without reversal of OA flow in these cases, flow parameters in the CRA and PCAs are also often found to be reduced. ${ }^{26}$ If reversal of flow is present this may also be detected in the supraorbital and supratrochlear arteries.

\section{Ophthalmic Artery Stenosis}

Ophthalmic artery stenosis is an infrequently diagnosed condition which has previously been reported in relation to amaurosis fugax, ${ }^{29,30}$ ocular ischaemic syndrome ${ }^{31}$ and diabetic retinopathy. ${ }^{32,33}$ On the colour Doppler image narrowing of the vessel may be noted if severe. Findings on spectral analysis include marked acceleration of blood flow across the stenotic segment of the vessel associated with post-stenotic turbulence (Kay et al., submitted for publication (Figs. 11, 12).

\section{Central Retinal Artery Occlusion}

In CRA occlusion acutely the CRA and CRV images are reduced or, rarely, absent on CDI. These findings are associated with reduced blood flow velocities and increased pulsatility of flow on spectral analysis (Figs. 13, 14). Occasionally a retrobulbar plaque suggesting the presence of an embolus is visible with CDI. The results of CDI in CRA occlusion have previously been found to correlate with fluorescein angiography findings (Lieb et al., unpublished data). We have also found that various therapeutic modalities employed to treat CRA occlusion acutely have had no effect on the CDI results. If there is a significant time delay between the onset of symptoms and the imaging procedure we have found that the CRA and CRV can once again be imaged more easily, presumably correlating with recanalisation of the CRA. Similar results have been reported elsewhere. ${ }^{34}$

\section{Central Retinal Vein Occlusion}

As previously stated, measurement of blood flow parameters in the CRV is often difficult to achieve. In those cases of CRV occlusion where this has been possible we have found that flow in the CRV is reduced in velocity and more pulsatile than normal. More consistently measurable are CRA parameters, and we have found that, in most cases, blood flow velocity in the CRA is reduced with a parallel increase in pulsatility (Fig. 15). It is currently unclear whether there is a significant difference in findings between ischaemic and non-ischaemic occlusions.

\section{Ischaemic Optic Neuropathy}

In cases of ischaemic optic neuropathy (ION) we have found consistently reduced flow parameters in the short PCAs. This finding has generally been more marked in cases associated with giant cell arteritis - as would be expected from clinical correlation. ${ }^{35}$ In non-arteritic ION it has been noted that optic nerve sheath decompression improves haemodynamic parameters as shown by $\mathrm{CDI} .^{36}$

\section{Giant Cell Arteritis}

Giant cell arteritis may be associated with CRA occlusion, ION and ophthalmic artery stenosis or occlusion. In our experience, and in that of others, ${ }^{37}$ the CDI findings when these clinical syndromes occur in relation to giant cell arteritis are more profound than in other cases, i.e. the vessels themselves are more difficult to image with the colour Doppler equipment and blood flow parameters as measured suggest more severe vessel involvement. These findings include markedly reduced blood flow velocities and highly elevated pulsatilities in posterior ciliary arteries and the CRA and frequently stenosis of the OA (Figs. 11, 12).

\section{Ocular Ischaemic Syndrome}

As has been previously described, in cases of ocular ischaemic syndrome blood flow parameters are usually reduced in both the CRA and PCAs. Reduced or reversed flow is also usually found in the OA (Fig. 10). ${ }^{27}$

\section{Carotid-Cavernous Fistula}

Carotid-cavernous fistula $(\mathrm{CCF})$ is a syndrome consisting of direct communication in the region of the cavernous sinus with the carotid arterial system - either the cavernous internal carotid (= direct, 'high-flow' CCF) or dural branches of the internal carotid and/or external carotid arteries. On a vascular basis this abnormal arteriovenous communication causes increased venous pressure with arterialisation of flow in those veins feeding into the cavernous sinus; in some cases it also causes reduced ophthalmic artery flow because of the direct shunting effect. The clinical ocular and orbital findings are well described elsewhere. $^{38}$

CDI studies show increased blood flow velocity with arterialisation of flow, i.e. development of a pulsatile arterial-type flow pattern in the SOV (Fig. 16). 5,39,40 


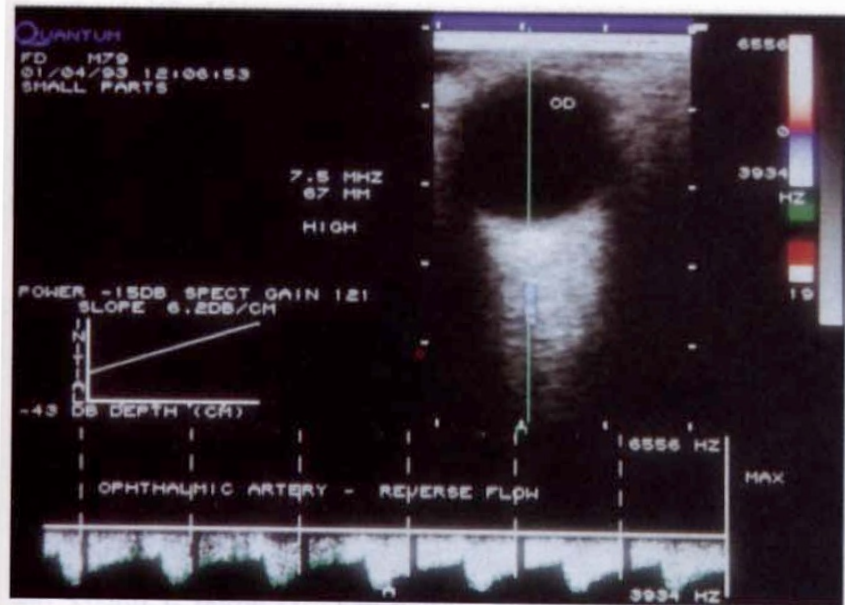

Fig. 10. CDI of right ophthalmic artery in a patient with total occlusion of the right internal carotid artery and ocular ischaemic syndrome. The blood flow is reversed in the ophthalmic artery as shown by the blue colour of the colour Doppler image and the negative waveform with spectral analysis.

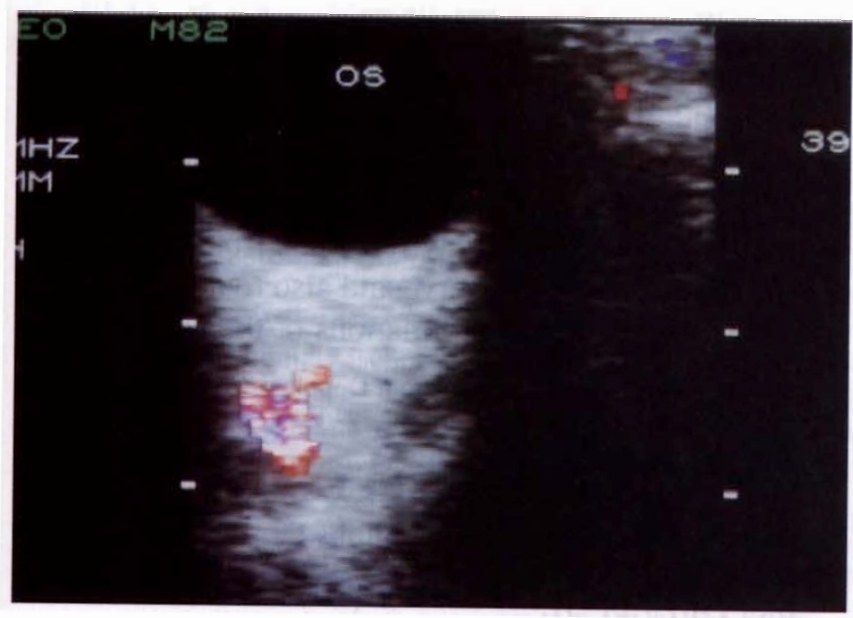

Fig. 12. Magnified colour Doppler image of a different view of the ophthalmic artery shown in Fig. 11. There is a mosaic pattern distally indicating post-stenotic turbulence.

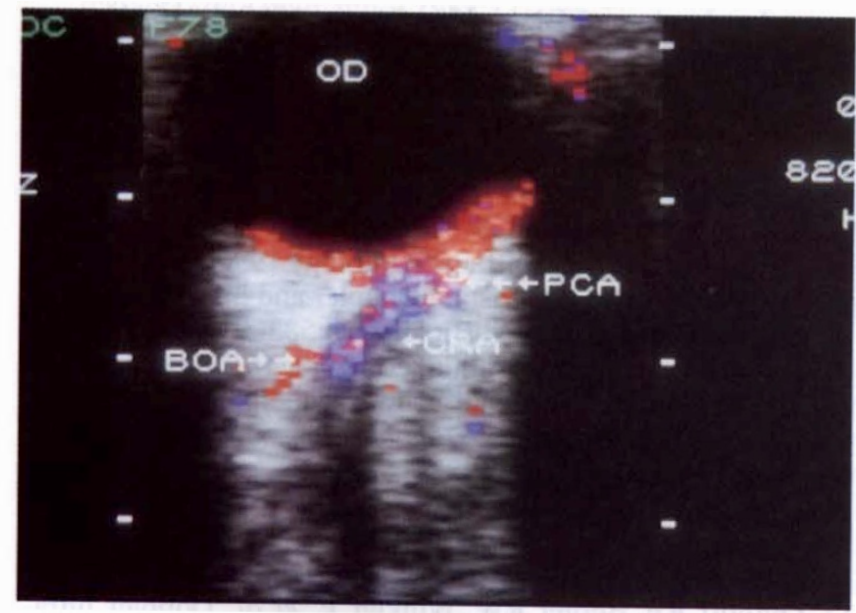

Fig. 14. Magnified colour Doppler image of a different view of the central retinal artery occlusion shown in Fig. 13. Note the minimal signal from distal central retinal artery. $B O A$, branch ophthalmic artery, i.e. proximal central retinal artery.

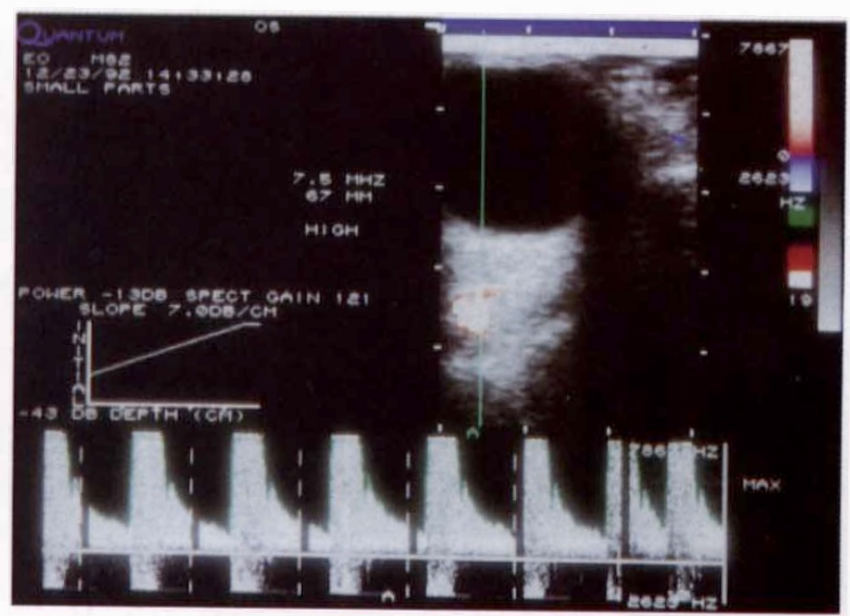

Fig. 11. CDI of ophthalmic artery stenosis in a patient with giant cell arteritis. Note the pale colour of the colour image of the ophthalmic artery and the truncated waveform with spectral analysis, both indicating very high blood flow velocities.

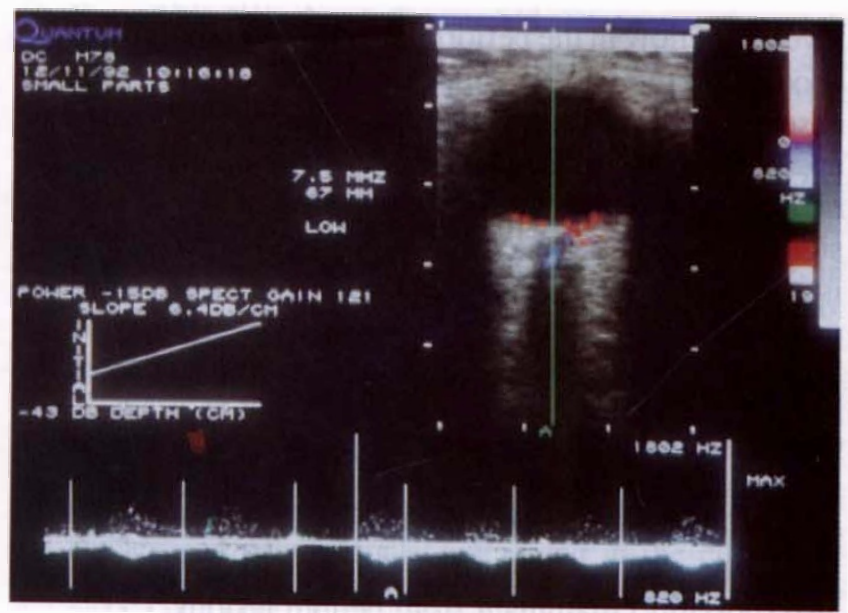

Fig. 13. CDI of a central artery occlusion showing a paucity of red pixels at the position of the central retinal artery and a lack of significant positive waveform on spectral analysis.

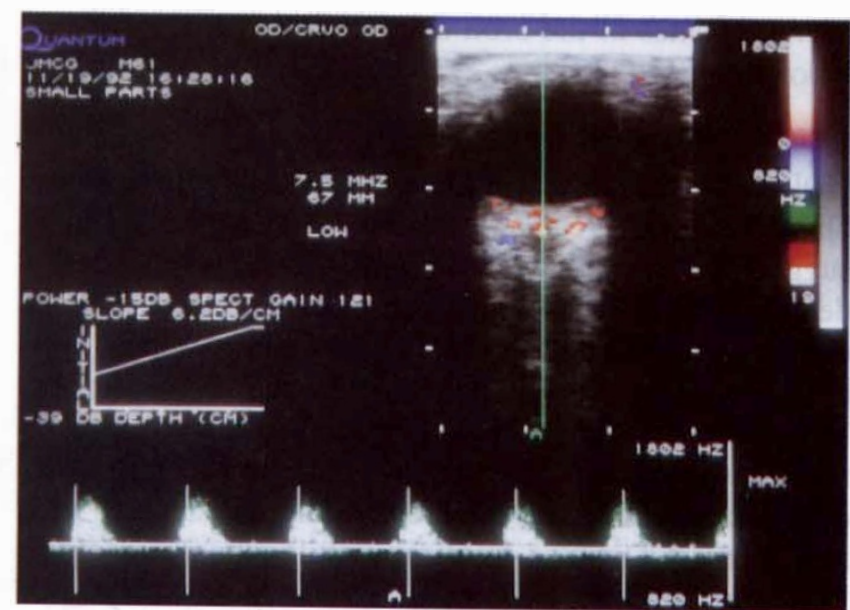

Fig. 15. Central retinal vein occlusion demonstrated with $C D I$ with reduced blood flow in central retinal artery and vein and increased central retinal artery pulsatility. 


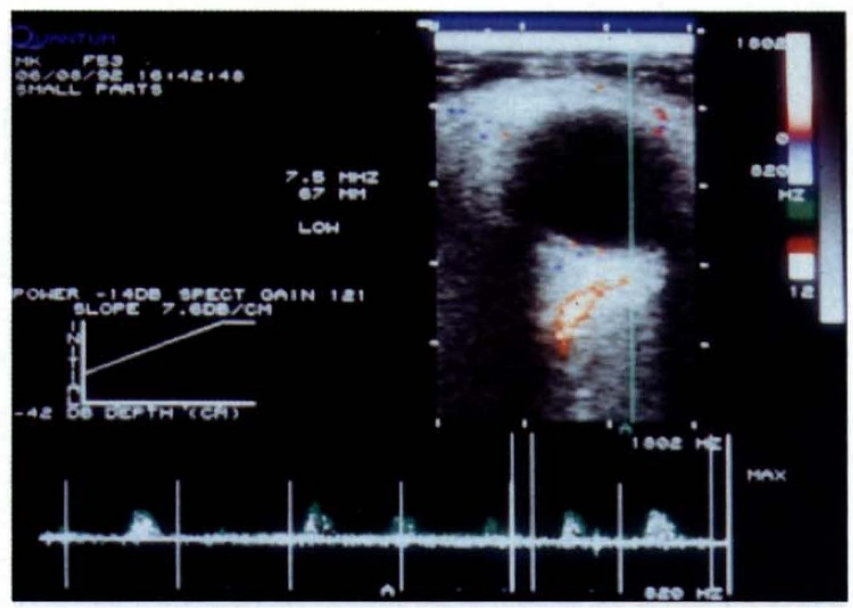

Fig. 16. Carotid-cavernous fistula showing reversal of blood flow in the superior ophthalmic vein (in red) and a reversed, pulsatile waveform with CDI.

Reduced OA flow is also sometimes detected. This imaging modality may also show proptosis, enlarged extraocular muscles, increased vascularity of the eyelids and reversal of flow in the periorbital veins. Also, with spontaneous resolution of this condition due to SOV thrombosis, absence of flow in the previously patent SOV may be apparent. This is useful as some patients who spontaneously resolve may suffer a worsening of symptoms and signs as this process occurs. ${ }^{41} \mathrm{CDI}$ may also show normalisation of blood flow parameters following active treatment of CCF.

\section{Orbital Tumours}

Orbital CDI would appear to have two main roles in the investigation of orbital masses. The first is the assessment of the vascularity of the tumours themselves, aiding in differentiation of vascular from non-vascular tumours and also (possibly) malignant from benign lesions.

CDI findings of an orbital varix have been reported as showing non-pulsatile influx and efflux of blood with more marked filling on the Valsalva manoeuvre and emptying on expiration. ${ }^{25,42}$ In comparison cavernous haemangiomas of the orbit show little or no evidence of blood flow (Fig. 17).

\section{Ocular Tumours}

CDI has been used by a number of investigators to assess blood flow in intraocular tumours. ${ }^{43-46}$ These studies have suggested that malignant intraocular lesions have easily demonstrable pulsatile and non-pulsatile blood flow as compared with benign lesions. These findings appear to be more marked in choroidal melanoma than in metastases. This method of blood flow detection can also be used to monitor the effects of treatment. Studies have shown that effective treatment of intraocular tumours results in a reduction of Doppler frequency shift signals recorded from such lesions, indicating reduced vascularity with therapy. ${ }^{45,46}$

\section{CONCLUSION}

In conclusion, $\mathrm{CDI}$ is an ultrasonic imaging technique

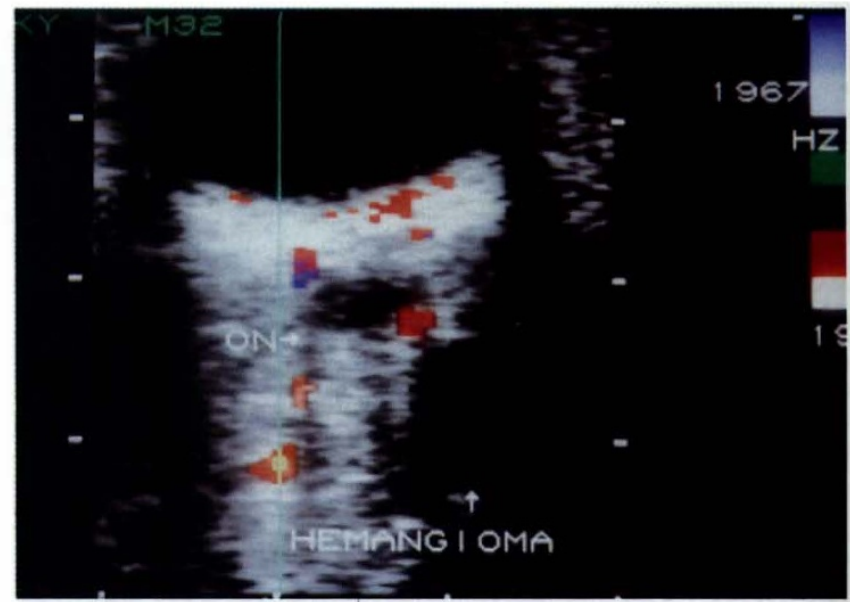

Fig. 17. CDI of cavernous haemangioma. Note the lack of blood flow signals from the tumour, suggesting low vascularity.

only recently introduced to ophthalmology and ophthalmologists. It has been shown to be of use in the diagnosis and management of a number of ocular and orbital conditions, but its precise role in the practice of ophthalmology is not entirely clear at this time. It seems likely, in our opinion, that this imaging modality will be accepted as of greatest use in the assessment of ocular and orbital diseases involving derangement of haemodynamic factors, particularly those conditions resulting from hypoperfusion of the eye and optic nerve and also to a lesser extent vascular tumours and malformations of the orbit.

Key words: Central retinal artery, Colour Doppler imaging, Ophthalmic artery, Optic nerve, Orbit, Posterior ciliary artery.

\section{REFERENCES}

1. Eyer MK, Brandestini MA, Phillips DJ, Baker DW. Color digital echo/Doppler image presentation. Ultrasound Med Biol 1981;7:21-31.

2. Mitchell DG. Colour Doppler imaging: principles, limitations, and artifacts. Radiology 1990;177:1-10.

3. Merritt CRB. Doppler color flow imaging. J Clin Ultrasound 1987; 15:591-7.

4. Powis RL. Colour flow imaging: understanding its science and technology. J Diagn Med Sonogr 1988;4:236-45.

5. Erickson SJ, Hendrix LE, Massaro BM, Harrsi GJ, et al. Color Doppler flow imaging of the normal and abnormal orbit. Radiology 1989;173:511-6.

6. Byrne SF, Green RL. Ultrasound of the eye and orbit. St. Louis: Mosby, 1991:1-16.

7. Taylor KJW, Holland S. Doppler US. Basic principles, instrumentation; and pitfalls. Radiology 1990;174:297-307.

8. White DN. Johann Christian Doppler and his effect: a brief history. Ultrasound Med Biol 1982;8:583-91.

9. Powis RL, Powis WJ. A thinker's guide to ultrasonic imaging. Baltimore: Urban and Schwarzenberg, 1984:171-200.

10. Canning CR, Restori M. Doppler ultrasound studies of the ophthalmic artery. Eye 1988;2:92-5.

11. Lieb WE, Flaharty PM, Ho A, Sergott RC. Color Doppler imaging of the eye and orbit: a synopsis of a 400 case experience. Acta Ophthalmol (Suppl) 1992;204:50-4.

12. Guthoff RF, Berger RW, Winkler P, et al. Doppler ultrasonography of the ophthalmic and central retinal vessels. Arch Ophthalmol 1991;109:532-6.

13. De Witt LD, Wechsler LR. Transcranial Doppler. Stroke 1988;19:915-21. 
14. Aaslid R, Markwalder T, Nornes H. Noninvasive transcranial Doppler ultrasound recording of flow velocity in basal cerebral arteries. J Neurosurg 1982;57:769-74.

15. Schneider PA, Rossman ME, Bernstein EF, et al. Noninvasive assessment of cerebral collateral blood supply through the ophthalmic artery. Stroke 1991;22:31-6.

16. Rojanapongpun P, Morrison B, Drance SM. Reproducibility of transcranial Doppler ultrasound examinations of the ophthalmic artery flow velocity. Br J Ophthalmol 1993;77:22-4.

17. Rojanapongpun P, Drance SM. Velocity of ophthalmic arterial flow recorded by Doppler ultrasound in normal subjects. Am J Ophthalmol 1993;115:174-80.

18. Gosling RG, King DH. Arterial assessment by Doppler-shift ultrasound. Proc R Soc Med 1974;67:447-9.

19. Lieb WE, Cohen SM, Merton DA, Shields JA, et al. Color Doppler imaging of the eye and orbit: technique and normal vascular anatomy. Arch Ophthalmol 1991;109:527-31.

20. Yoshii I, Ikeda A. A new look at the blood supply of the retro-ocular space. Anat Rec 1992;233:321-8.

21. Hayreh SS, Dass R. The ophthalmic artery. II. Intraorbital course. Br J Ophthalmol 1962;46:165-85.

22. Tane S, Hasimoto T. Estimation of blood flow in the carotid artery and intraorbital artery by colour pulse Doppler ultrasonography. Acta Ophthalmol (Suppl) 1992;204 4:62-5.

23. Last RJ. Wolff's anatomy of the eye and orbit. 6th ed. Philadelphia: Saunders, 1968:30-181.

24. Hayreh SS. The ophthalmic artery. III. Branches. Br J Ophthalmol 1962;46:212-47.

25. Berges O. Colour Doppler flow imaging of the orbital veins. Acta Ophthalmol (Suppl) 1992;204:55-8.

26. Lieb WE, Flaharty PM, Sergott RC, et al. Colour Doppler imaging provides accurate assessment of orbital blood flow inocclusive carotid artery disease. Ophthalmology 1991;98: $548-42$.

27. Ho AC, Lieb WE, Flaharty PM, et al. Color Doppler imaging of the ocular ischemic syndrome. Ophthalmology 1992;99:1453-62.

28. Tatemichi TK, Chamorro A, Petty GW, et al. Hemodynamic role of ophthalmic artery collateral in internal carotid artery occlusion. Neurology 1990;40:461-4.

29. Weinberger J, Bender AN, Yang WC. Amaurosis fugax associated with ophthalmic artery stenosis: clinical simulation of carotid artery disease. Stroke 1980;11:290-3.

30. Aasen J, Kerty E, Russell D, et al. Amaurosis fugax: clinical, Doppler and angiographic findings. Acta Neurol Scand 1988;77:450-5.

31. Brown GC, Magargal LE. The ocular ischemic syndrome: clinical, fluorescein angiographic and carotid angiographic features. Int Ophthalmol 1988;1 1:239-51.

32. Garner A, Ashton N. Ophthalmic artery stenosis and dia- betic retinopathy. Trans Ophthalmol Soc UK 1972;7: 101-10.

33. Michelson G, Gierth-Viebig K, Laumer R. Gepsulste Doppler-sonographie der A. ophthalmica bei retinopathia diabetica proliferans. Fortschr Ophthalmol 1990;87:551-3.

34. Berger RW, Guthoff R, Helmke K, et al. Farbkodierte Doppler-sonographie orbitaler Gefaesse unter besonderer Berucksichtigung der Arteria und Vena centralis retinae. Fortschr Ophthalmol 1991;88:690-3.

35. Boghen DR, Glaser JS. Ischaemic optic neuropathy: the clinical profile and natural history. Brain 1975;98:689-708.

36. Flaharty PM, Sergott RC, Bosley TM, Savino PJ. Changes in ocular blood flow after optic nerve sheath decompression in non-arteritic optic neuropathy. Ophthalmology 1993;100: 299-302.

37. Williamson TH, Baxter G, Paul R, Dutton GN. Colour Doppler ultrasound in the management of a case of cranial arteritis. Br J Ophthalmol 1992;76:690-1.

38. Sanders MD, Hoyt WF. Hypoxic ocular sequelae of carotidcavernous fistulae. Br J Ophthalmol 1969;53:82-97.

39. Flaharty PM, Lieb WE, Sergott RC, et al. Colour Doppler imaging: a new non-invasive technique to diagnose and monitor carotid cavernous fistulas. Arch Ophthalmol 1991;109:522-6.

40. Kotval PS, Weitzner I, Tenner MS. Diagnosis of carotidcavernous fistula by periorbital color Doppler imaging and pulsed Doppler volume flow analysis. J Ultrasound Med 1990;9:101-6.

41. Sergott RC, Grossman RI, Savino PJ, et al. The syndrome of paradoxical worsening of dural-cavernous sinus arteriovenous malformations. Ophthalmology 1987;94:205-12.

42. Lieb W, Merton D, Shields J, et al. Color Doppler imaging in the demonstration of an orbital varix. $\mathrm{Br} \mathrm{J}$ Ophthalmol 1990;74:305-8.

43. Falco L, Esente S, Fanfani S, et al. Our experience in the diagnosis of intraocular tumors by a B-scan computerized system and angiodynography (Doppler): preliminary results. Acta Ophthalmol (Suppl) 1992;204:76-80.

44. Wolff-Korman PG, Kormann BA, Hasenfratz GC, et al. Duplex and color Doppler ultrasound in the differential diagnosis of choroidal tumors. Acta Ophthalmol (Suppl) 1992;204:66-70.

45. Lieb WE, Shields JA, Cohen SM, et al. Color Doppler imaging in the management of intraocular tumors. Ophthalmology 1990;97:1660-4.

46. Guthoff RF, Berger RW, Winkler P, et al. Doppler ultrasonography of malignant melanoma of the uvea. Arch Ophthalmol 1991;109:537-41. 